\title{
The interannual relationship between MJO activity and tropical cyclone genesis in the Indian Ocean
}

\author{
Aya Tsuboi and Tetsuya Takemi
}

\begin{abstract}
The present study investigated the relationship between the interannual variations of Madden-Julian Oscillation (MJO) and tropical cyclone genesis (TCG) over the Indian Ocean during the October-November-December season by conducting statistical analyses with the use of 33-year reanalysis data. Through dividing the 33-year period into the active year and the non-active year of MJO, we identified the characteristics of TCG in the active and the non-active year. Environmental conditions for TCG under the influence of the MJO activity were diagnosed by an empirical index, Genesis Potential Index (GPI). It was shown that TCG events over the Indian Ocean in the active year are significantly increased when the convectively active phase of MJO develops over the Indian Ocean and the Maritime Continent. GPI in the active (non-active) year showed positive (negative) anomaly over almost the whole Indian Ocean. In addition, TCG is enhanced (suppressed) in the area of positive (negative) GPI anomaly. Diagnosing the factors constituting GPI showed that relative humidity and vertical velocity have more pronounced contributions than the other factors of GPI. The present analyses demonstrate that the activity of MJO has an influence on the inter-annual relationship of TCG through the modulation of environmental conditions.
\end{abstract}

Keywords: Tropical cyclone; Madden-Julian oscillation; Indian Ocean; Genesis potential index

\section{Background}

The generation and development of tropical cyclones (TCs) are regulated by their background conditions such as horizontal and vertical shears, thermodynamic stability, moisture distribution, and sea surface temperature. The interannual variation of tropical cyclone genesis (TCG) is considered to be strongly influenced by El Niño/La Niña and Southern Oscillation (ENSO), which controls the background conditions for not only TCG in the Pacific Ocean $[1,2]$ but also that in the Indian Ocean (IO) [3-5].

There are other tropical oscillations that influence TCG through modifying the background conditions for TCs. One of the oscillations that affect the TCG variation is the Madden-Julian Oscillation (MJO; [6]) which is the most dominant mode of the intraseasonal variations of the tropical atmosphere and is quite variable year by year. It is reasonable to assume that $\mathrm{MJO}$ also has an impact on the interannual variation of TCG.

Previous studies examined the influences of MJO on TCG and showed that TCG is enhanced during the active

\footnotetext{
* Correspondence: takemi@storm.dpri.kyoto-u.ac.jp

Disaster Prevention Research Institute, Kyoto University, Gokasho, Uji, Kyoto
} 611-0011, Japan

\section{Springer}

(c) 2014 Tsuboi and Takemi; licensee Springer. This is an Open Access article distributed under the terms of the Creative Commons Attribution License (http://creativecommons.org/licenses/by/2.0), which permits unrestricted use, distribution, and reproduction in any medium, provided the original work is properly credited. phase of MJO in the IO [7-9]. The IO is unique in the sense that the signal of MJO over the IO is more pronounced than over the other ocean basins. However, these studies focused on the timescales within the active phase of MJO (i.e., within an intraseasonal timescale). There are no studies to assess the impacts of MJO on the interannual variation of TCG in a climatological perspective. If the amplitude of the MJO variability is high, it is considered that the impacts of MJO on TCG should be significant even compared to those of ENSO. The active phase of MJO is in general found in the IO, the Maritime Continent, and the western Pacific. Therefore, the present study focuses on the TCG over the IO and during the season of October, November, and December to indicate a possible influence of the MJO activity on the interannual variation of TCG in the IO. By focusing on the IO from October to December in which the activity of MJO is high, we expect that the MJO influences should be highlighted.

The purpose of this study is to investigate the climatological relationship between the interannual variations of MJO and TCG in the IO and to examine the environmental conditions that affect the variation of TCG which 
occurs under the influence of the MJO activity by using an empirical index: Genesis Potential Index (GPI; $[10,11])$. For this purpose, we use long-term reanalysis data over 33 years and compare the differences of TCG and environmental conditions between the years of active MJO and non-active MJO over the IO by dividing the analysis years depending on the activity of MJO.

\section{Methods}

Statistical analyses are conducted with the use of 33-year dataset during 1979 and 2011 to examine the relationship between the interannual variations of MJO activity and TCG in the IO. We specifically focus on the season of October, November, and December (OND) during when the convectively active phase of MJO frequently appears. This season is also characterized by the enhanced frequency of TCG over the IO both in the northern and southern hemisphere. Figure 1 shows the locations of TCG in each season from the best-track data during 1979 and 2011. It is clearly seen that TCG frequently occurs over the whole IO in the OND season.

The TC best-track dataset of the United States Navy's Joint Typhoon Warning Center (JTWC) is used for identifying the locations of TCG over the IO during the period between 1979 and 2011. In order to examine the environmental conditions for TCG, we use the reanalysis dataset produced by Japan Meteorological Agency (JMA) and the Central Research Institute of Electric Power Industry: the Japanese 25-year Reanalysis (JRA-25)/JMA Climate Data Assimilation System (JCDAS) dataset [12]. The JRA-25/ JCDAS dataset has a horizontal resolution of 1.25 degree and 6-hour temporal interval starting from 1979. This dataset was widely used in assessing the environmental conditions for TCG over the Indian Ocean [13-15], over the western North Pacific $[11,16]$, and over the Atlantic [17]. The representation of TCG environments in different reanalysis datasets including the JRA-25/JCDAS data can be found in Menkes et al. [18]; it is not seen that there are no pronounced differences among the datasets.

We divide the 33 years into MJO active years and $\mathrm{MJO}$ non-active years and compare the characteristics between the two categories. The MJO index of Wheeler and Hendon [19], archived at Australian Government Bureau of Meteorology and commonly referred to in MJO-related studies, is used to define the active years and the non-active years of MJO. The MJO index of Wheeler and Hendon is represented by two variables: real-time multivariate MJO series 1 (RMM1) and series 2 (RMM2), and is demonstrated by the phase space of RMM1 and RMM2. In the phase space, the amplitude of $\mathrm{MJO}$ is determined by the distance from the phase-space center, i.e., the square root of the sum of RMM1 squared and RMM2 squared. Phases 1 to 8 mean the approximate locations of enhanced convective signal of MJO. For example, phases 2 and 3 correspond to the period when MJO is active over the IO, and phases 4 and 5 correspond to the Maritime Continent. Phases 2-5 are chosen to divide active and non-active year from the total analysis years.

The procedure to define the MJO active year and the non-active year is described here. Firstly, we count a number of days in which the amplitude of an MJO event
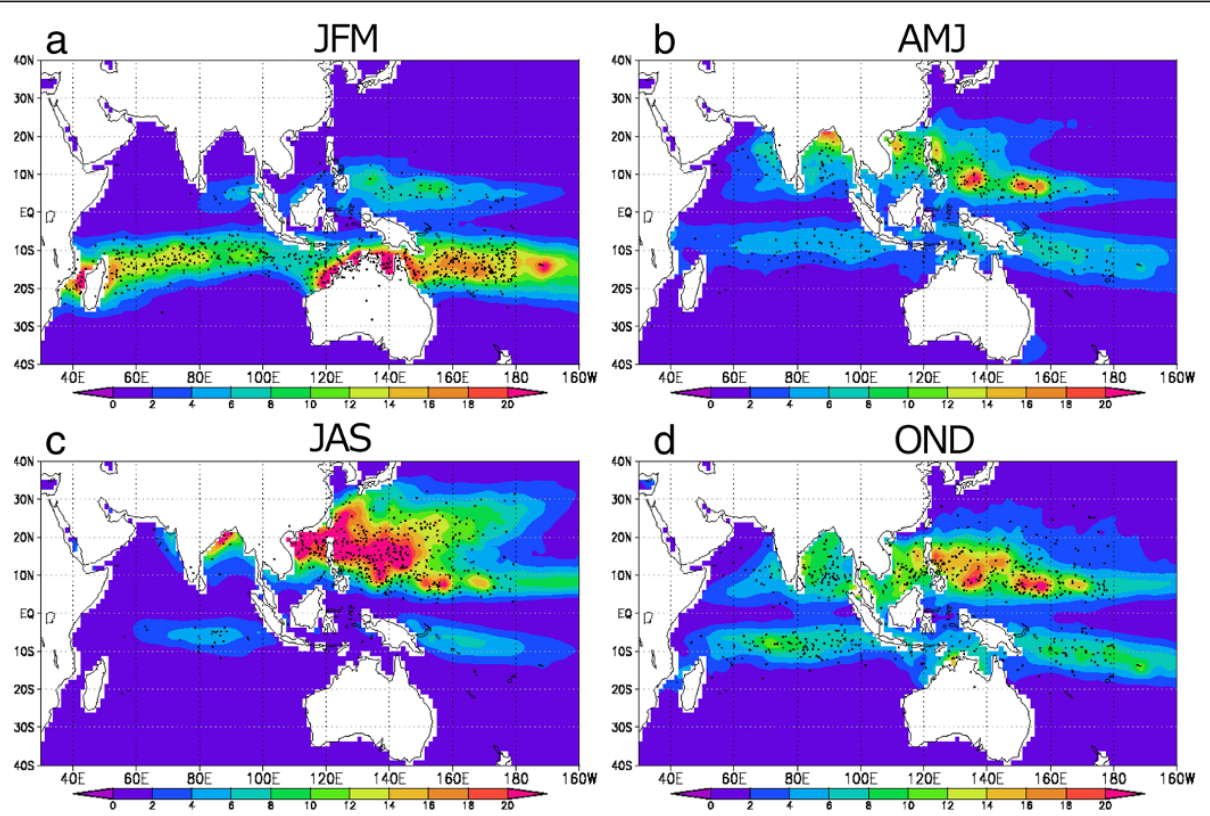

Figure 1 The spatial distribution of averaged GPI (color) and TCG locations (black dots) during the period of 1979-2011: (a) JanuaryFebruary-March (JFM), (b) April-May-June (AMJ), (c) July-August-September (JAS), and (d) October-November-December (OND). 
is larger than 1.0 in the phase space and at the same time the MJO phase shows any phase among phases 2, 3 , 4, and 5 during the season of OND in each year. Secondly, we calculate the mean and standard deviation of the number of days of active MJO from the 33-year time series. Finally, the active (non-active) year is defined as a year in which the number of the active days is larger (smaller) than a half of the standard deviation from the 33-year mean. From this procedure, 11 years, i.e., 1979, 1982, 1984, 1987, 1993, 1994, 1999, 2000, 2002, 2008, and 2011, out of the 33 years are determined as active years, and 11 years, i.e., 1980, 1981, 1985, 1988, 1991, 1992, 1995, 1998, 2004, 2005, and 2010, are determined as non-active years. We did not apply any detrending of the dataset from the consideration that any trends that might exist in the dataset would be minimized by compositing data in each year category. Note that both the active and the non-active years include El Niño and La Niña phases.

To assess environmental conditions favorable/unfavorable for TCG, we use a genesis potential index (GPI) of Murakami et al. [11] that is a modified version of GPI originally defined by Emanuel and Nolan [10]. The GPI of Murakami et al. is defined as follows:

$$
\mathrm{GPI}=\left|10^{5} \eta\right|^{\frac{3}{2}}\left(\frac{R H}{50}\right)^{3}\left(\frac{V_{p o t}}{70}\right)^{3}\left(1+0.1 V_{s}\right)^{-2}\left(\frac{-\omega+0.1}{0.1}\right)
$$

where $\eta$ is the absolute vorticity $\left(\mathrm{s}^{-1}\right)$ at the $850-\mathrm{hPa}$ level, $R H$ is the relative humidity (\%) at the $700-\mathrm{hPa}$ level, $V_{\text {pot }}$ is the maximum potential intensity (MPI; $\mathrm{m} \mathrm{s}^{-1}$ ) of Emanuel [20], $V_{s}$ is the magnitude of the vertical wind shear $\left(\mathrm{m} \mathrm{s}^{-1}\right)$ between the levels of 850 and $200 \mathrm{hPa}$, and $\omega$ is the vertical wind speed $\left(\mathrm{Pa} \mathrm{s}^{-1}\right)$ at the $500-\mathrm{hPa}$ level. Murakami et al. suggested that the vertical velocity term, which was newly added to the original GPI of Emanuel and Nolan [10], enables better reproducibility of TC genesis over regions with strong ascending motion due to the Inter-Tropical Convergence Zone and other convective circulation. The computation of MPI was conducted with the use of the Fortran code obtained from the Emanul's web site (ftp://texmex.mit.edu/pub/ emanuel/TCMAX/pcmin_revised.f).

The JRA-25/JCDAS dataset is used to compute GPI. As shown in Figure 1 GPI seems to well represent the spatial distribution of observed TCG as the 33-year climatology. GPI was used in diagnosing environments for TCG under the MJO conditions $[8,14,21]$, because it is considered that the index takes into account the effects of low-level vorticity, vertical shear, middlelevel humidity, and static stability including sea surface temperature which are important ingredients for TCG [22]. Therefore we regard GPI as a tool to diagnose environmental conditions for TCG and the relationship between MJO activity and TCG. Note that it is an open question whether and how GPI or other empirical indices can explain the interannual variation of TCG [18], and it may be the case that appropriate indices differ depending on the oceanic basins.

\section{Results and discussion}

In order to demonstrate how the observed TCG differs between the active year and the non-active year of MJO, we examine the MJO phase at times of the initial identification of TCs and count the number of TCG events for each phase. Figure 2 indicates the genesis locations converted to the points in the phase space and the ratios (in percentage) of the number of TCG events at each MJO phase to the total number of TCG events. Points indicate the days when TCG occur (black dots) in the RMM1 and RMM2 space and the percentages denote the number of TCGs for each MJO phase to the total number of TCG. It is seen that in the active year the percentages of TCG events are higher in phases 2-5 than in the other phases while in the non-active year the percentages in phases $2-5$ are similar to those in the other phases. In addition, the percentages in phases 2 and 3 in the active year are more pronounced, which suggests that the number of TCG events is remarkably increased when MJO develops actively over the IO and the Maritime Continent.

The spatial distributions of TCG in the active year and in the non-active year are shown in Figure 3. Figure 3 also demonstrates the anomalies of GPI composited over the active years and the non-active years compared with the 33-year mean during the OND season. There is clearly a difference of GPI anomalies between the active year and the non-active year. The GPI anomaly in the active year shows positive values in the IO except in the $5^{\circ} \mathrm{S}-15^{\circ} \mathrm{S}$ band to the east of the $80^{\circ} \mathrm{E}$ longitude and near the coastal lines of the Bay of Bengal. In contrast, the spatial pattern of the anomaly in the non-active year appears to be opposite to that of the active year. Negative

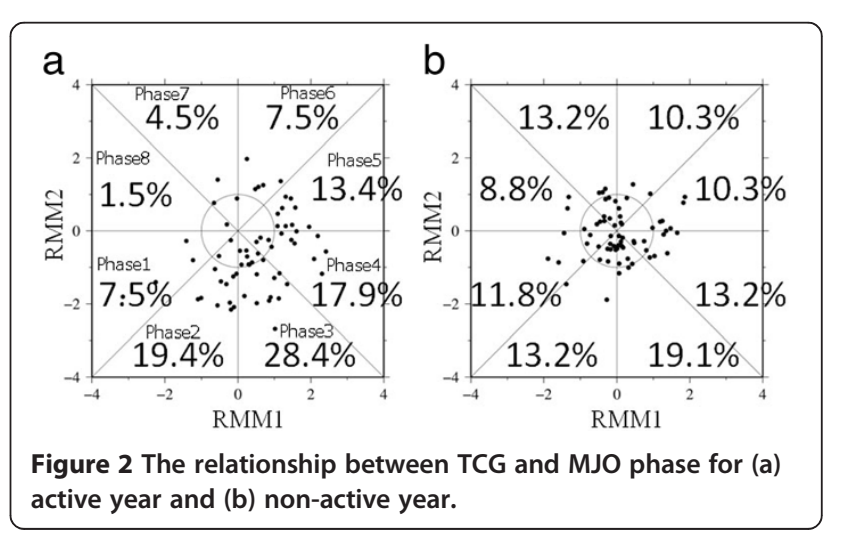



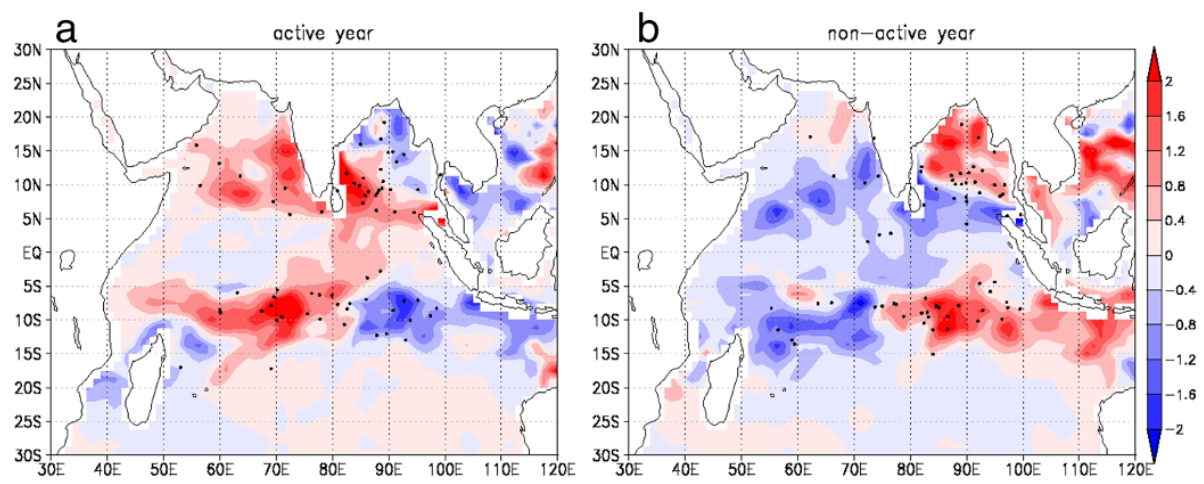

Figure $3 \mathrm{GPI}$ anomalies (color) and the TCG points (black dots) in (a) the active year and (b) the non-active year.

values extend in the IO except in the southeastern part of the IO and in the Bay of Bengal. It is also found in Figure 3 that the total number of the TCG locations is larger in the positive-anomaly region than in the negative-anomaly region: the number of TCG events in the region of positive GPI anomaly is 45 (45) while that that in the region of negative GPI anomaly is 20 (21) during the active year (the non-active year). Thus, in both the active and the non-active year more TCG occurs over the region with positive GPI anomaly from the climatology. In this way GPI is considered to be an important environmental parameter for TCG in the Indian Ocean.

Because there is a regional pattern in the distributions in Figure 3, the IO region of $50-100^{\circ} \mathrm{E}$ and $20^{\circ} \mathrm{S}-20^{\circ} \mathrm{N}$ is divided into four sub-regions. The statistical significance for the difference of the GPI anomalies between the active year and the non-active year is assessed for these four sub-regions. Table 1 summarizes GPI anomalies averaged for each four region, i.e., the northwestern IO (NWI), the northeastern IO (NEI), the southwestern IO (SWI), and the southeastern IO (SEI) in the active year and the non-active year. It is indicated that the differences of the GPI anomalies between the active year and the non-active year in NWI and SWI are statistically significant at $95 \%$ confidence level.

Considering that there is a significant difference of the GPI anomaly between the active year and the non-active year, we examine the degree of contributions from the

Table $1 \mathrm{GPI}$ anomalies averaged for each region in the active year and non-active year and its differences for the whole Indian Ocean (IO), the northwestern IO (NEI), the northeastern IO (NEI), the southwestern IO (SWI), and the southeastern IO (SEI)

\begin{tabular}{cccccc}
\hline & IO & NWI & NEI & SWI & SEI \\
\hline Active & 0.28 & 0.41 & 0.39 & 0.38 & -0.20 \\
Non-active & -0.16 & -0.41 & 0.04 & -0.40 & 0.37 \\
Difference & $0.44^{*}$ & $0.82^{*}$ & 0.34 & $0.78^{*}$ & -0.57 \\
\hline
\end{tabular}

The values with asterisk are statistically significant at $95 \%$ confidence level. five factors constituting GPI (see Eq. (1)) to the total GPI anomaly in the active year. In calculating the contributions we follow the procedure of Camargo et al. [8,23]. First, the 33-year mean of each factor in GPI is obtained in calculating the 33-year mean of total GPI at each grid point. After determining the 33-year means, we re-calculate the GPI values by using the means of four out of the five factors but by using varying 6-hourly values for the fifth factor. This is repeated for each of the other four factors; the anomaly of each factor composited in the active year is recalculated in terms of the GPI value. Therefore the degree of contribution of each factor to the GPI anomaly is derived.

Figure 4 compares the contribution of each factor in terms of GPI value for the active year. Note here that the summation of all the 5 factors in terms of GPI (Figure 4b-4f) is equivalent to the total GPI anomaly (Figure 4a). The comparison of the spatial patterns in Figure $4 \mathrm{~b}-4 \mathrm{f}$ with that in Figure $4 \mathrm{a}$ indicates that the area of pronounced contribution of each factor to the GPI anomaly depends on the region within the IO. In the NWI and SWI region relative humidity and vertical velocity contribute most significantly to the total GPI anomaly, while in SEI vorticity, MPI, and vertical velocity contribute to the negative anomaly of GPI. Over the whole IO, the patterns of relative humidity and vertical velocity seem to be similar to that of the total GPI anomaly.

The contribution of each factor to the total GPI anomaly was examined also for the non-active year (not shown). It was seen that the spatial pattern in the IO for the nonactive case was similar, but with opposite signs, to that for the active case shown in Figure 4. Again, the patterns of the contributions from relative humidity and vertical velocity seemed to be similar to that of the GPI anomaly shown in Figure $3 b$.

The similarity of the spatial patterns is examined in terms of the spatial correlation coefficients between the total GPI anomaly and the degree of contribution of each factor to the total GPI anomaly in both the active 


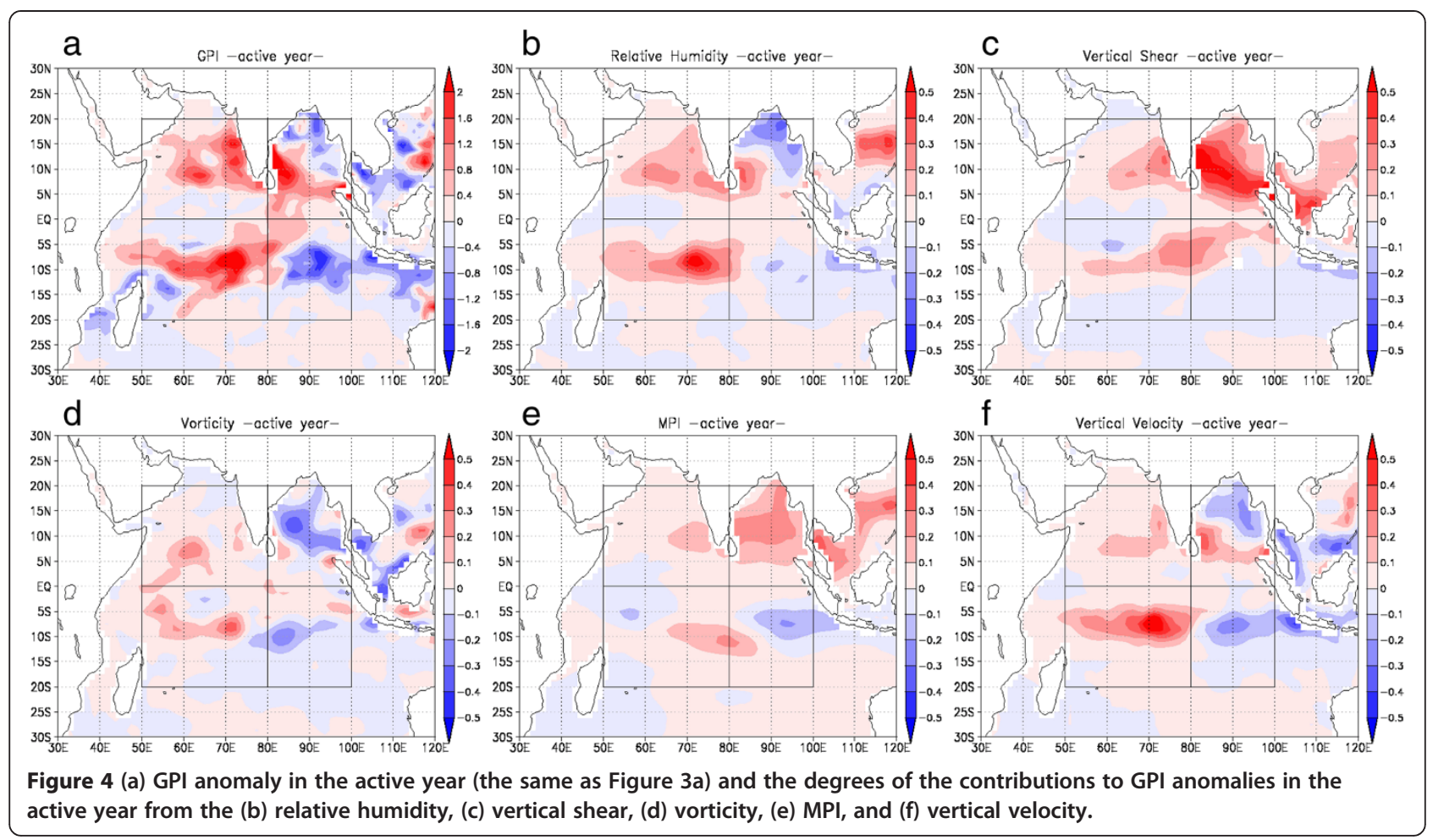

and the non-active year, which are evaluated over the whole IO. The results are summarized in Table 2. The degrees of contribution of relative humidity and vertical velocity indicate high correlations with the total GPI anomalies in both the active and the non-active year. This means that these two factors have a closer relationship with the total GPI anomaly than the other factors in the whole IO region. It is thus suggested that the spatial distribution of relative humidity and vertical motion controls the pattern of the GPI anomaly over the IO. If higher relative humidity and enhanced ascending motion, modulated by enhanced convection due to active $\mathrm{MJO}$, exist over the IO, the positive anomaly of GPI is induced, which affects the locations of TCG.

\section{Conclusions}

By using long-term reanalysis data during 33 years, i.e., the JRA-25/JCDAS dataset, this study investigated the statistical relationship between the interannual variations

Table 2 Correlation coefficients of the spatial distributions in the whole 10 between total GPI anomalies and GPI anomalies for varying each factor in the active and non-active year

\begin{tabular}{cccccc}
\hline & RH & VS & VOR & MPI & $\boldsymbol{\omega}$ \\
\hline Active & 0.72 & 0.51 & 0.37 & 0.43 & 0.75 \\
Non-active & 0.71 & 0.28 & 0.49 & 0.15 & 0.69
\end{tabular}

RH, VS, VOR, MPI and $\omega$ denote relative humidity, vertical shear, vorticity, MPI and vertical velocity, respectively. of MJO activity and TCG over the IO and identified the environmental conditions that affect the variation of TCG which occurs under the influence of the MJO activity. The environmental conditions were diagnosed by GPI. The OND season was focused since both the MJO activity and the number of TCG events are high in the IO in this season. We divided the analysis period into the active year and the non-active year of MJO, thereby indicating characteristic environmental conditions for TCG in high MJO activity.

As a 33-year climatology, it was indicated that the number of TCG events over the IO is significantly increased when the convectively active phase of $\mathrm{MJO}$ develops over the IO and the Maritime Continent. An environmental parameter for the TCG, that is, GPI, in the active year showed positive anomaly over almost the whole IO except in the northern NEI region and the SEI. In contrast, the spatial distribution of GPI in the nonactive year showed opposite to that in the active year. If the number of TCG events was counted over the region only with positive or negative anomaly of GPI, the TCG number was larger over the positive anomaly region than over the negative anomaly region; TCG is enhanced (suppressed) in the area of positive (negative) GPI anomaly.

The degrees of contribution of each five factor constituting GPI to the total GPI value are different in four sub-regions of the IO. It was shown that in the whole IO relative humidity and vertical velocity most 
significantly contribute to the GPI anomalies. Through such modulation of environmental condition for TCG, observed TCG is considered to be modulated by MJO.

The present analyses demonstrate that the activity of MJO has an influence on the interannual variation of TCG through the modulation of environmental conditions. Although the variation of ENSO is considered to be the most dominant mode of interannual variations of the tropical atmosphere including TCG, the MJO activity also plays a role in determining the interannual variation of TCG. Delayed influences of ENSO on the atmospheric variability and TCG over the IO [24] should also be investigated.

\begin{abstract}
Abbreviations
ENSO: El Niño/La Niña and Southern Oscillation; GPI: Genesis potential index; IO: The Indian Ocean; JCDAS: JMA climate data assimilation system; JMA: Japan meteorological agency (JMA); JRA-25: The Japanese 25-year reanalysis; JTWC: Joint typhoon warning center; MJO: Madden-Julian oscillation; MPI: Maximum potential intensity; NEl: The northeastern Indian Ocean; NWI: The northwestern Indian Ocean; OND: October, November, and December; RMM1: Real-time multivariate MJO series 1; RMM2: Real-time multivariate MJO series 2; SEl: The southeastern Indian Ocean; SWI: The southwestern Indian Ocean; TCG: Tropical cyclone genesis.
\end{abstract}

\section{Competing interests}

The authors declare that they have no competing interests.

\section{Authors' contributions}

AT carried out the statistical analysis of the atmospheric data and drafted the manuscript. TT supervised the data analysis and the interpretation of the results and completed the final manuscript. Both authors read and approved the final manuscript.

\section{Authors' information}

AT was a graduate student at the Division of Earth and Planetary Sciences, Kyoto University, and doing research as her master's thesis at Disaster Prevention Research Institute, Kyoto University. TT is an associate professor at the Research Section of Severe Storm and Atmospheric Environment, Disaster Prevention Research Institute, Kyoto University. The research topics of $T$ are related to dynamics and physics of mesoscale and microscale meteorological phenomena including turbulence, local circulation, severe storms, thunderstorms, precipitating cloud systems, tropical cyclones, and extratropical cyclones through data analysis, numerical modeling, and numerical simulations. The Tा's research topic also covers tropical meteorology such as air-sea interaction processes and moist convection.

\section{Acknowledgments}

We would like to thank two anonymous reviewers for their comments in improving the original manuscript. This study was supported by Scientific Research grant number 24651207 from Japan Society for the Promotion of Science.

\section{Received: 18 November 2013 Accepted: 27 March 2014}

Published: 28 April 2014

\section{References}

1. Chia HH, Ropelewski CF (2002) The interannual variability in the genesis location of tropical cyclones in the northwest Pacific. J Clim 15:2934-2944

2. Wang B, Chan JCL (2002) How strong ENSO events affect tropical storm activity over the Western North Pacific. J Clim 15:1643-1658

3. Ho CH, Kim JH, Jeong JH, Kim HS (2006) Variation of tropical cyclone activity in the south Indian Ocean: El Niño-Southern Oscillation and Madden-Julian Oscillation effects. J Geophys Res 111, D22101

4. Girishkumar MS, Ravichandran M (2012) The influence of ENSO on tropical cyclone activity in the Bay of Bengal during October-December. J Geophys Res 117, C02033
5. Ng EKW, Chan JCL (2012) Interannual variations of tropical cyclone activity over the north Indian Ocean. Int J Climatology 32:819-830

6. Madden RA, Julian PR (1972) Description of global-scale circulation cells in the Tropics with a 40-50 day period. J Atmos Sci 29:1109-1123

7. Liebmann BB, Hendon HH, Glick JD (1994) The relationship between tropical cyclones of the western Pacific and Indian Oceans and the Madden-Julian oscillation. J Meteor Soc Japan 72:401-412

8. Camargo SJ, Wheeler MC, Sobel AH (2009) Diagnosis of the MJO modulation of tropical cyclogenesis using an empirical index. J Atmos Sci 66:3061-3074

9. Bessafi M, Wheeler MC (2006) Modulation of south Indian Ocean tropical cyclones by the Madden-Julian Oscillation and convectively coupled equatorial waves. Mon Weather Rev 134:638-656

10. Emanuel KA, Nolan DS (2004) Tropical cyclone activity and global climate. In: Preprints of the 26th Conference on Hurricanes and Tropical Meteorology, Miami, Florida., pp 240-241

11. Murakami H, Wang B, Kitoh A (2011) Future change of Western North Pacific typhoons: projections by a $20-\mathrm{km}$-mesh global atmospheric model. J Clim 24:1154-1169

12. Onogi K, Tsutsui J, Koide H, Sakamoto M, Kobayashi S, Hatsushika H, Matsumoto T, Yamazaki N, Kamahori H, Takahashi K, Kadokura S, Wada K, Kato K, Oyama R, Ose T, Mannoji N, Taira R (2007) The JRA-25 reanalysis. J Meteor Soc Japan 85:369-432

13. Kikuchi K, Wang B (2010) Formation of tropical cyclones in the northern Indian Ocean associated with two types of tropical intraseasonal oscillation modes. J Meteor Soc Japan 88:475-496

14. Yanase W, Satoh M, Taniguchi H, Fujinami H (2012) Seasonal and intraseasonal modulation of tropical cyclogenesis environment over the Bay of Bengal during the extended summer monsoon. J Clim 25:2914-2930

15. Murakami H, Sugi M, Kitoh A (2013) Future changes in tropical cyclone activity in the north Indian Ocean projected by high-resolution MRI-AGCMs. Clim Dyn 40:1949-1968

16. Yoshida R, Kajikawa Y, Ishikawa H (2014) Impact of boreal summer intraseasonal oscillation on environment of tropical cyclone genesis over the Western North Pacific. SOLA 10:15-18

17. Wang R, Wu L (2013) Climate changes of Atlantic tropical cyclone formation derived from twentieth-century reanalysis. J Clim 26:8995-9005

18. Menkes $C E$, Lengaigne $M$, Marchesiello P, Jourdain NC, Vincent EM, Lefevre J, Chauvin F, Royer JF (2012) Comparison of tropical cyclogenesis indices on seasonal to interannual timescales. Clim Dyn 38:301-321

19. Wheeler MC, Hendon HH (2004) An all-season real-time multivariate MJO index: Development of an index for monitoring and prediction. Mon Weather Rev 132:1917-1932

20. Emanuel KA (1995) Sensitivity of tropical cyclones to surface exchange coefficients and a revised steady-state model incorporating eye dynamics. J Atmos Sci 52:3969-3976

21. Huang P, Chou C, Huang R (2011) Seasonal modulation of tropical intraseasonal oscillations on tropical cyclone geneses in the Western North Pacific. J Clim 24:6339-6352

22. Gray WM (1975) Tropical cyclone genesis in the western North Pacific. Naval Postgraduate School, Monterey, California, Technical Paper 16-75

23. Camargo SJ, Emanuel KA, Sobel AH (2007) Use of a genesis potential index to diagnose ENSO effects on tropical cyclone genesis. J Clim 20:4819-4834

24. Lau NC, Nath MJ (2003) Atmosphere-ocean variations in the Indo-Pacific sector during ENSO episodes. J Clim 16:3-20

doi:10.1186/2196-4092-1-9

Cite this article as: Tsuboi and Takemi: The interannual relationship between MJO activity and tropical cyclone genesis in the Indian Ocean. Geoscience Letters 2014 1:9. 